THE IOURNAL OF INFECTIOUS DISEASES - VOL. 160, NO. 5 - NOVEMBER 1989

(C) 1989 by The University of Chicago. All rights reserved. $0022-1899 / 89 / 6005-0018 \$ 01.00$

\title{
Host Factors Selectively Increase Staphylococcal Adherence on Inserted Catheters: A Role for Fibronectin and Fibrinogen or Fibrin
}

\author{
Pierre Vaudaux, Didier Pittet, André Haeberli, \\ Elzbieta Huggler, Urs E. Nydegger, Daniel P. Lew, \\ and Francis A. Waldvogel
}

\author{
From the Division of Infectious Diseases, Department of \\ Medicine, University Hospital, Geneva, and the Thrombosis \\ Research Laboratory, Department of Medicine, University \\ Hospital, and SRC Blood Transfusion Service, \\ Bern, Switzerland
}

\begin{abstract}
Intravascular catheters are prone to staphylococcal infections. To study the role in staphylococcal adherence played by fibrinogen or fibrin and fibronectin deposited on inserted catheters, 187 peripheral or central cannulae were prospectively removed from hospitalized patients. Compared with uninserted catheters, which allowed only minimal adherence, previously inserted catheters promoted significant adherence of staphylococcal isolates from patients with intravenous device infections. Adhesion-promoting properties were studied with laboratory strains having well-defined affinities for either fibronectin or fibrinogen: adherence of Staphylococcus aureus Cowan I, which has the highest affinity for both adhesins, was more strongly promoted (10- to 50-fold) on inserted cannulae than was that of $S$. aureus Wood 46 (4- to 10-fold) or Staphylococcus epidermidis Rp 12 (2.2-fold), which has no affinity for fibrinogen but does for fibronectin. Although all types of cannulae contained significant amounts of fibrin, which may promote adherence of coagulase-positive staphylococci, results obtained with coagulase-negative isolates suggested that in vivo-deposited fibronectin is also a critical determinant in this process.
\end{abstract}

Infectious complications associated with the use of intravascular (iv) catheters have been reported to occur in 1\%-40\% of cases [1-3]; these devices are important causes of nosocomial sepsis $[1,3-5]$ and candidemia [3,5]. A major contributing factor in iv device-related infection is the transcutaneous cannula wound allowing microorganisms from the patient's skin flora to migrate across the skin barrier. The microbial colonization of the transcutaneous part of the catheter has been identified as a sensitive index of catheter-associated bacteremia [6]. The establishment of a fibrin sheath [1] surrounding the blood-exposed cannula may favor bacterial attachment and promote bacterial replication around the intravascular part of the catheter. The thrombogenicity of plastic materials plays a role in their associ-

Received for publication 28 December 1988 and in revised form 30 May 1989.

This work was presented in part at the First World Congress of Hospital Infection, 1-3 September 1987, London, UK.

This work was supported by grant 3.829.0.-87 from the Swiss National Research Foundation.

The authors thank the nurses of the Clinique Medicale Thérapeutique for help in collecting catheters and B. Chapuis, Oncology Unit, for providing Hickman catheters.

Please address requests for reprints to Dr. Pierre Vaudaux, Division of Infectious Diseases, Department of Medicine, University Hospital, $\mathrm{CH}-1211$ Geneva 4, Switzerland. ation with device-related infections [7]; the risks of phlebitis increase with duration of insertion and severity of underlying diseases [8]. Finally, impaired host mechanisms secondary to the presence of foreign implants might play a role in catheter-associated infections as for other implants [9].

Intravenous catheters are most often colonized by staphylococci [6, 10-12]. Staphylococcus aureus was initially considered the predominant species in cannula-related septicemia, and Staphylococcus epidermidis has recently been identified as a major pathogen of these infections [13, 14]. A number of studies [15-24] have shown that most coagulasenegative strains of staphylococci infecting intravascular lines produce an extracellular fibrous matrix, designated either as slime [15-17, 19-22] or glycocalix $[18,23,24]$. This material is assumed to help coagulase-negative staphylococci colonize the indwelling devices [15-25] and resist host defense mechanisms [26, 27] and antibiotics [28].

The role of host-derived adhesins in promoting staphylococcal adherence to intravascular devices has not been reported despite the large amount of recent information on the in vitro interaction of staphylococci with a variety of host macromolecules, such as fibrinogen or fibrin [29-32], fibronectin [32-45], laminin [46], and collagen [37, 47]. Each of these host-derived adhesins, when present in ade- 
quate amounts, should be able to promote staphylococcal adherence to intravascular devices. However, experimental data to support the clinical relevance of such interactions are lacking.

We have previously shown that fibronectin deposited on polymethylmethacrylate (PMMA) tissue cages that were implanted subcutaneously into guinea pigs significantly contributed to increased in vitro staphylococcal adherence [48]. The specific contribution of fibronectin in promoting $S$. aureus Wood 46 adherence was established by incubating explanted coverslips with antibodies to fibronectin and demonstrating that such antibodies prevented further attachment of the protein A-deficient strain of $S$. aureus used in that study [48]. We also developed a simplified in vitro assay system by using purified fibronectin adsorbed onto PMMA coverslips. Under these circumstances, this host protein promoted $S$. aureus Wood 46 adherence by several times [49], a process specifically inhibited by antibodies to fibronectin [48].

More recent studies have extended these observations to other types of biomaterials [50,51], protein coats [52], and staphylococcal strains tested: most clinical isolates associated with intravenous device infections showed increased adherence in this experimental system [52]. In particular, 0 of 27 coagulase-positive and -negative bacteremic isolates from intravenous device infections could attach to the native polymers coated with whole serum or albumin [52] whereas adherence of all clinical isolates was restored by coating the polymers with fibronectin [52]. In contrast, fibrinogen-coated polymers promoted adherence of all clinical isolates of coagulase-positive staphylococci but of only a few coagulase-negative isolates [52]. Here we report that upon insertion, intravenous devices became coated with blood components promoting adherence of various staphylococcal strains; this increased adherence appears to be related to strain-specific affinities for surfacebound fibronectin and fibrinogen or fibrin.

\section{Materials and Methods}

Collection of catheters. We prospectively removed intravascular venous catheters from adult medical inpatients and from outpatients of our oncology unit (Hickman catheters) at the Geneva University Hospital. All iv catheters were removed consecutively during a period of $6 \mathrm{mo}$, and clinical and laboratory data for each patient were collected on a case report form. At the time of catheter removal, the venipuncture site was examined for the presence of swelling, erythema, lymphangitis, local warmth, tenderness, and palpable venous thrombosis.

Further clinical and laboratory data collected were: age, gender, diagnosis, duration of implantation, anatomic location of catheter placement, number of preceding catheter insertions, drugs and solution(s) infused, presence of fever or positive blood cultures, prescription of drugs interfering with blood coagulation, and function of the catheter. The following laboratory values were collected: sedimentation rate, leukocyte count and differential, platelet count, and partial thromboplastin (when available) and prothrombin times.

There is no "iv team" at our institution, and no antimicrobial ointment is used for prevention of infection. Catheters were removed by two nurses trained by one of us (D. P.). The time of catheter removal was decided by each patient's physician. Catheters were withdrawn by using sterile forceps while flushing with glucose $5 \%$ or $\mathrm{NaCl} 0.9 \%$, immersed immediately in tubes containing sterile $\mathrm{NaCl}$ $0.9 \%$ at $4^{\circ} \mathrm{C}$, and stored at $-70^{\circ} \mathrm{C}$. Only the strictly intravascular part of each catheter was considered in this study. Wen a catheter infection was suspected, semiquantitative cultures as described by Maki [6] were performed using $4-5 \mathrm{~cm}$ of the catheter tip; $<10 \%$ showed $>15$ colony forming units (cfu). Such culture-positive cannulae were not included in the present study. No patient in this series had devicerelated bacteremia.

The following types of catheters were tested: Teflon 17-gauge (Venflon; Viggo AB, Helsingborg, Sweden); fluoropolyethylene (Abbocath; Abbott, Sligo, Ireland; polyvinyl chloride (PVC) 14-gauge (Drum-Cartridge; Abbott) and 16- and 19-gauge (Intracath; Deseret Pharmaceutical, Sandy, Utah); and Hickman 9.6-French single lumen (Evermed, Cranston, RI).

Chemicals and materials. Phosphate-buffered saline (PBS) solutions without divalent cations or

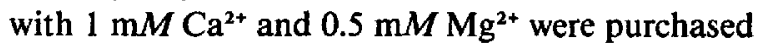
from Gibco (Paisley, Scotland) and $\left[{ }^{3} \mathrm{H}\right]$ thymidine from Amersham (Buckinghamshire, UK). Purified fibronectin, prepared as previously described [48], and human serum albumin were provided by $J$. J. Morgenthaler (Central Laboratory of the Swiss Red Cross Blood Transfusion Service, Bern). Purified fibrinogen (Imco, Stockholm) was further purified 
from traces of fibronectin by chromatography on gelatin-sepharose [48]. Coverslips $(1 \times 1 \mathrm{~cm})$ made of PMMA were prepared as previously described [48].

Bacterial strains. Three laboratory strains of staphylococci were used in a bioassay screening for the presence of fibronectin or fibrinogen on inserted cannulae: $S$. aureus Cowan I and Wood 46, whose adherence is promoted by both surface-bound fibrinogen and fibronectin, and $S$. epidermidis $\mathbf{R p}$ 12 (provided by G. Christensen, Memphis), whose adherence is promoted by surface-bound fibronectin only. In addition, 10 strains (five $S$. aureus, five coagulase-negative) of a previously described [52] group of 27 bacteremic isolates from iv device infections were tested for adherence on inserted cannulae.

In vitro adherence assays. Radiolabeled bacteria were prepared as previously described [52]. Detailed conditions for in vitro coating of PMMA coverslips with purified proteins and for assaying adherence of staphylococci have been described previously $[48,49,52]$. We used a constant inoculum of $4 \times 10^{6} \mathrm{cfu}$ for the adherence assays, whose purpose was to define the attachment properties of the laboratory strains selected for the bioassay of fibronectin and fibrinogen. To verify that the affinities of each strain were not influenced by variable concentrations of surface-bound fibronectin or fibrinogen, we tested bacterial adherence on PMMA coverslips precoated by exposure to a wide range of concentrations $(1-32 \mu \mathrm{g} / \mathrm{ml})$ of either purified protein in solution.

The adherence-promoting effect of either fibronectin or fibrinogen was also tested on native, uninserted catheters by incubating $1-\mathrm{cm}$-long segments with different concentrations of purified fibronectin or fibrinogen as described with PMMA coverslips and by performing the adherence assay as described above with a constant inoculum $\left(4 \times 10^{6}\right.$ $\mathrm{cfu} / \mathrm{ml})$ of each strain [48, 49]. At the end of the attachment period, cannula segments were rinsed and $\mathrm{cfu}$ of staphylococci bound specifically to fibronectin- or fibrinogen-coated cannulae were estimated by using radioactive counts as previously described [48, 49]. An adherence-promoting effect was defined as the increase in adherence over background values recorded in parallel on the same, but albumincoated, cannula segments $[48,49,52]$. Indeed, the presence of $5 \mathrm{mg} / \mathrm{ml}$ of human serum albumin in the incubation medium of the adherence assay effi- ciently prevented nonspecific adherence to native uninserted cannula segments of various types, as previously reported with PMMA coverslips $[48,49,52]$.

Adherence assay of catheters removed from patients. In vitro staphylococcal adherence to cannulae withdrawn from hospitalized patients was recorded as follows: $1-\mathrm{cm}$-long duplicate segments of the intravascular parts of previously inserted catheters were incubated with a constant inoculum $\left(4 \times 10^{6} \mathrm{cfu} / \mathrm{ml}\right)$ of the above-mentioned laboratory strains or bacteremic isolates of staphylococci. The adherence medium was supplemented with human serum albumin as described above to minimize nonspecific attachment to cannula areas that might be unexposed to plasma proteins (e.g., the lumen). All conditions for assaying staphylococcal adherence on inserted cannulae were the same as those described above for uninserted coverslips, which were systematically run in parallel as controls.

Validation of the adherence assay. Although the adherence assay, whether performed with inserted or uninserted catheters, was a simple extension of a previous assay performed on PMMA [48, 49, 52] or Teflon [50] coverslips, we were concerned about the possible trapping of radiolabeled bacteria within the lumen of cannula segments, which would lead to erroneous adherence values. Thus in some experiments, as indicated, we compared adherence properties of cannula segments that were split longitudinally before the adherence assay and unsplit cannula segments. The purpose of splitting was to allow optimal rinsing of radiolabeled bacteria from the lumen. For uninserted cannulae, which were always tested in parallel with inserted ones, we found an equivalent adherence of $S$. aureus Wood 46 on either split (median, $6.1 \times 10^{2} \mathrm{cfu} ; n=15$ ) or unsplit (median, $7.1 \times 10^{2} \mathrm{cfu} ; n=15$ ) segments.

Radioimmunoassay of fibrinogen or fibrin. The procedure for estimating the total amount of fibrinogen or fibrin recovered from the intravascular parts of cannulae removed from patients has been previously described in detail [53]. Briefly, 1-cm-long sections of the cannulae were digested at $37^{\circ} \mathrm{C}$ for 24 $\mathrm{h}$ in $1 \mathrm{ml}$ of PBS supplemented with $0.1 \mathrm{ml}$ of plasminogen $(40 \mu \mathrm{g})$ previously activated to plasmin by $3,000 \mathrm{IU}$ of urokinase. After removal of a $0.1-\mathrm{ml}$ portion of the solubilized fibrinogen and fibrin fragments, cannulae were again digested for a further 24-h period using the same technique, to ensure complete digestion of the cannula-associated fibrinogen or fibrin. The 24- or 48-h digests were assayed for 
the amount of the late soluble fragment E, which remains stable under these conditions [53]. From the amount of fragment $E$, estimated by a radioimmunoassay using a specific antiserum [53], the quantity of cannula-associated fibrinogen or fibrin was calculated on the basis of a molecular weight ratio of 48,500 for fragment $E$ to 340,000 for native fibrinogen.

Statistical evaluation of data. All adherence data were normalized to a constant inoculum of $4 \times 10^{6}$ $\mathrm{cfu} / \mathrm{ml}$, which corrected for minor day-to-day and strain-to-strain variations in the yield of radiolabeled bacteria tested. Adherence data recorded on inserted versus uninserted cannulae were compared by nonparametric statistical tests, the Mann-Whitney test for unrelated rankable scores and the Wilcoxon matched pairs test for related rankable scores. Correlation of adherence data with fibrinogen and fibrin content of inserted cannulae were evaluated by Pearson's product moment coefficients, as determined by using programs adapted to an HP 41-C computer (Hewlett-Packard, Geneva).

\section{Results}

Figure 1 shows one representative experiment assaying adherence of 10 bacterial strains, isolated from iv device infections, on consecutive $1-\mathrm{cm}$ segments of a single long PVC catheter (Drumcath), previously inserted for $48 \mathrm{~h}$. Compared with the same, but not previously inserted material, the inserted catheter promoted a significantly higher adherence $(P<.05$, Wilcoxon matched pairs test) of all bacteremic isolates as tested in triplicate assays. The median bacterial adherence of the five $S$. aureus isolates was more strongly enhanced (10.8-fold) than was adherence of the five coagulase-negative isolates (2.8-fold; $P<.05$, Mann-Whitney test). Adherence of all bacteremic strains, whether coagulase-positive or -negative, was uniform when tested on uninserted control catheter segments tested in parallel (figure 1). These contrasting adherence data for inserted versus uninserted cannulae suggested a role in this process by blood components deposited on inserted iv lines.

To further investigate this process in a larger group of patients, we tested the characteristics of staphylococcal adherence on 50 short cannulae (Venflon) previously inserted for 12-48 h. Figure 2 shows that cannulae removed from the patients significantly promoted adherence of either laboratory strain $\mathrm{Co}$ wan I or Wood 46 of $S$. aureus over the minimal ad-

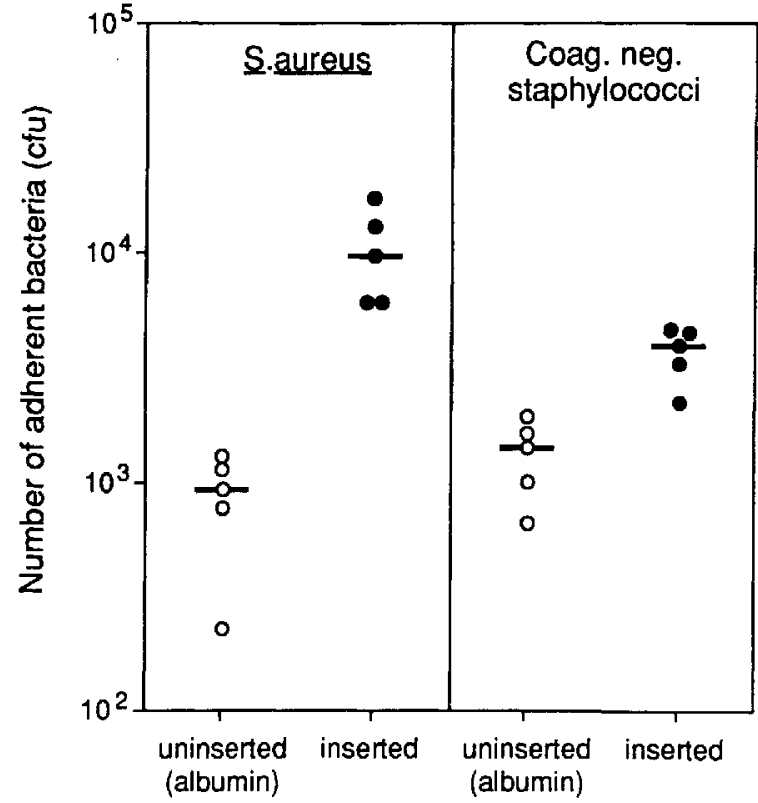

Figure 1. Adherence of ten bacteremic strains from iv device infections, five $S$. aureus and five coagulase-negative staphylococci, to either uninserted (albumin-coated) or inserted $1-\mathrm{cm}$ segments of a long peripheral polyvinyl chloride (Drumcath) catheter. Value for each strain represents the average of triplicate determinations; bars indicate median adherence of each group of strains.

herence of either strain recorded on albumin-coated, uninserted cannulae. This increase in adherence promoted by inserted over uninserted catheters was significantly larger $(P<.001$, Mann-Whitney) for strain Cowan I (12.8-fold) than for strain Wood 46 (4.1-fold). Similarly, as shown in figure 2 , in vitro precoating of uninserted cannulae with fibronectin $(25 \mu \mathrm{g} / \mathrm{ml})$ significantly increased adherence of either staphylococcal strain, $S$. aureus Cowan I being promoted to a higher extent than Wood 46 (29.8-and 6.8-fold, respectively, $P<.01$, Mann-Whitney). Thus, adherence to inserted cannulae may have reflected different affinities of the strains for fibronectincoated cannulae.

Although our results pointed to a contribution of surface-bound fibronectin in promotion of staphylococcal adherence to inserted catheters, the role of fibrinogen or fibrin also had to be evaluated in this context. To study the contribution of fibrinogen or fibrin deposited on inserted catheters, we tested long peripheral cannulae which, after removal from patients, were incubated with three different laboratory strains selected for their markedly different affinities for surface-bound fibrinogen and fibronectin 


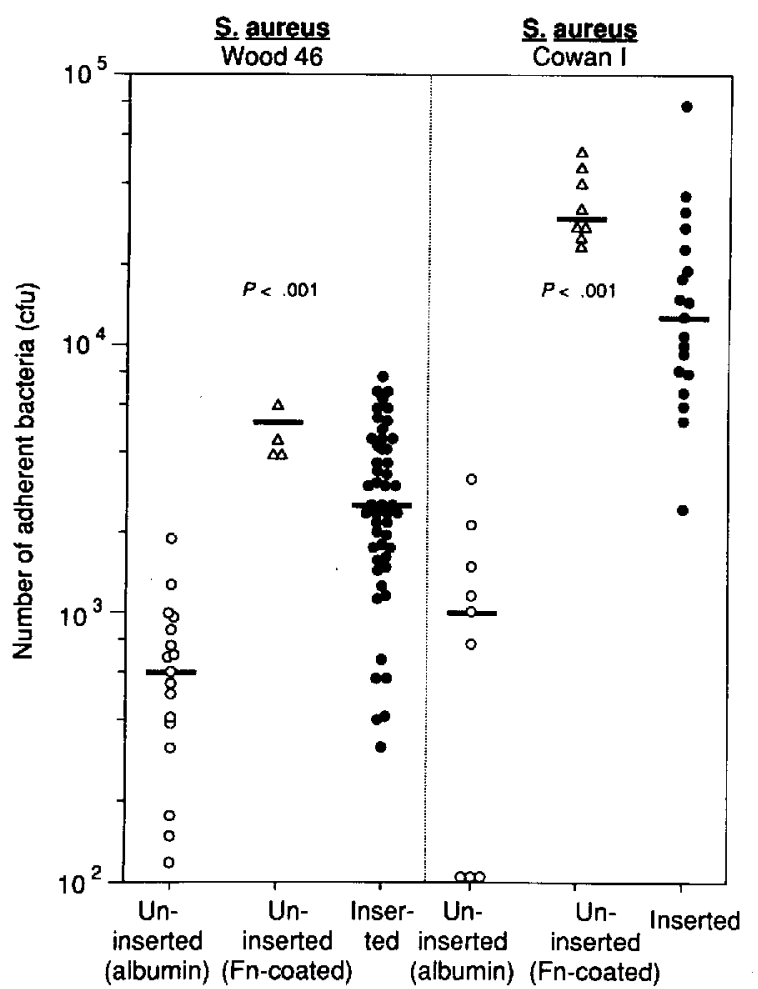

Figure 2. Adherence of two laboratory strains of $S$. aureus on either uninserted (albumin- or fibronectin [Fn]coated) or inserted peripheral Venflon catheters. Each value represents the average of duplicate determinations of staphylococcal adherence; bars indicate median values for each group.

(figure 3A). Indeed, adherence of each laboratory strain was differently and selectively promoted on the segments of inserted cannulae (figure 3B).

Although segments of the long cannulae were split longitudinally before the adherence assay in this experiment, we could rule out that this procedure significantly influenced the adherence data, since another group of inserted cannulae of the same type but left unsplit showed similar results (not shown). Indeed, $S$. aureus Cowan I, having the highest affinity for both fibrinogen and fibronectin, showed the strongest adherence increase (49.4-fold) on inserted over uninserted cannulae (figure 3B). Compared with that of $S$. aureus Cowan I, adherence of both other strains on inserted cannulae was less but still significantly increased for either $S$. aureus Wood 46 (4.5-fold, $P<.01$, Mann-Whitney) or $S$. epidermidis Rp 12 (2.2-fold, $P<.002$, Mann-Whitney) over that on uninserted cannulae (figure 3B). Adherence of $S$. epidermidis Rp 12 to plasma proteins depos- ited on inserted catheters suggested that fibronectin was mainly responsible for this process, since this strain showed no affinity for surface-bound fibrinogen (figure 3A).

To compare how different categories of catheters used in various clinical situations promoted bacterial adherence, we removed from patients another series of 124 cannulae and classified them into four groups according to materials and to venous site of insertion (central or peripheral). All groups of cannulae produced a similar pattern (figure 4) and promoted significantly ( $P<.01$, Mann-Whitney) by 5 - to 12 fold the adherence of $S$. aureus Wood 46 over uninserted control cannulae. There were no significant differences between the various types of catheters in distribution of adherence within each group, including the Venflon cannulae used for comparison. Both observations led us to conclude that staphylococcal adherence was influenced by factors specific for each individual patient, which could affect adsorption of blood components onto their cannulae.

To further document the deposition of blood proteins on the surface of inserted cannulae, we measured the total amount of fibrinogen and fibrin present on 47 catheters representative of the five different types previously tested for adherence (figure 4). Although deposition was highly variable within each group, all types of cannulae contained deposits of significant amounts of fibrinogen or fibrin that were easily detectable by radioimmunoassay (figure 5).

To evaluate whether this variable deposition could be related to clinical or laboratory parameters, patients were separated into two subgroups of similar size according to the amount of fibrinogen or fibrin coating the removed catheters. The median duration of catheter insertion was not significantly different $(P>$.1, Mann-Whitney) for patients of the "lowfibrin" group ( $7 \mathrm{~d}, 0.2-4.7 \mu \mathrm{g} / \mathrm{cm}$ of cannula) and those of the "high-fibrin" group ( $8 \mathrm{~d}, 8.1-112 \mu \mathrm{g} / \mathrm{cm})$. There was no significant difference in severity of illness of patients in either group, the proportion of cardiovascular, pulmonary, and neoplastic diseases or septic conditions in either group being the same. The proportion of patients showing a catheter malfunction tended to be higher, although at the limit of significance ( $P=.06$, two-tailed Fisher's exact test), in the low-than in the high-fibrin group; a similar proportion of patients in either group had macroscopic thrombi at the cannulae tips during removal (table 1). 

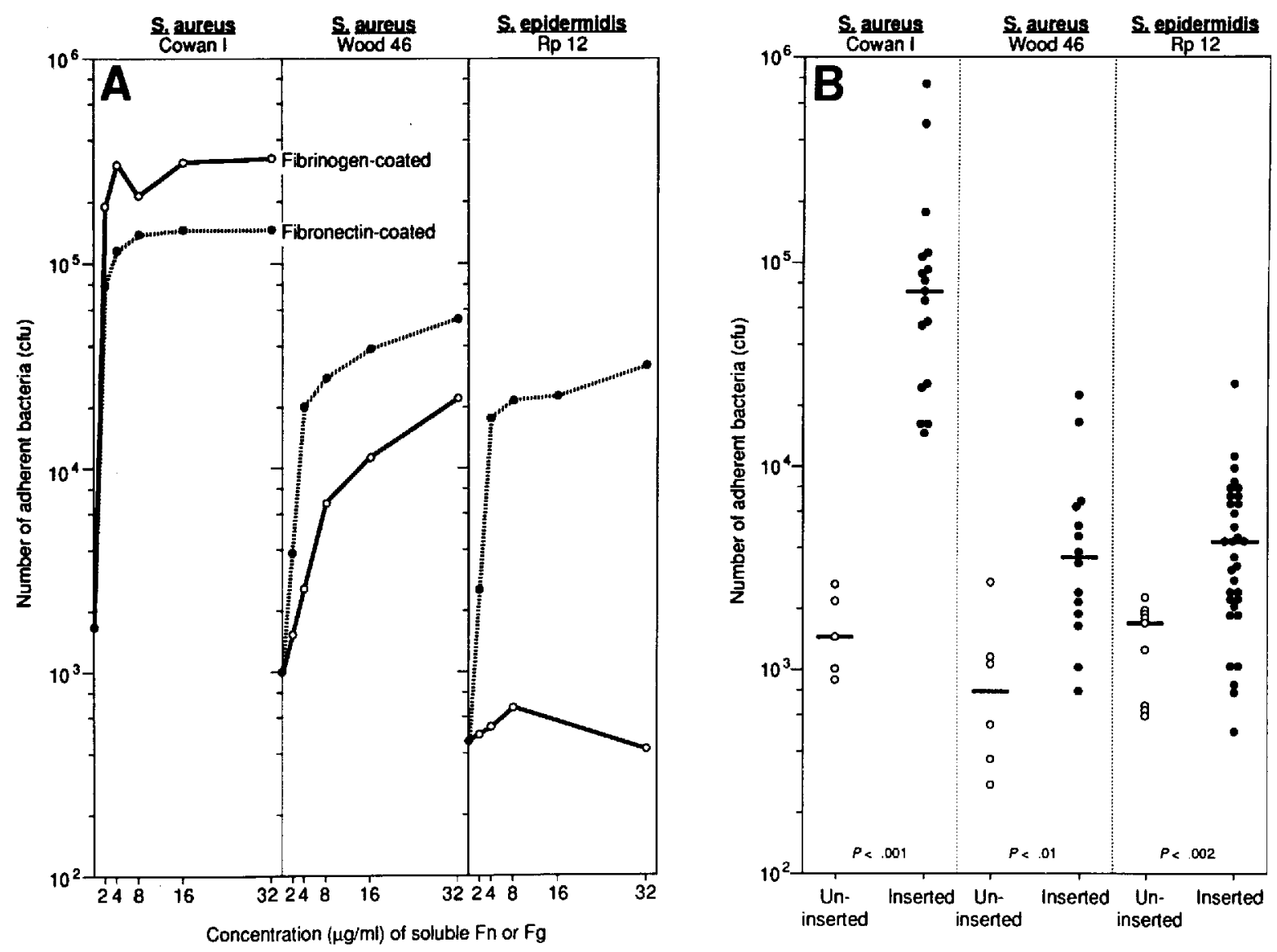

Figure 3. Promotion of staphylococcal adherence (three laboratory strains) by in vitro coating of polymethylmethacrylate coverslips with purified fibrinogen $(\mathrm{Fg})$ or fibronectin $(\mathrm{Fn})$ at indicated concentrations $(A)$ or by blood components deposited in vivo on inserted polyvinyl chloride catheters $(B)$. Assay was done on duplicate coverslips or 1-cm sections split longitudinally. Bars indicate median values for each group.

An effect of perfused products on the fibrinogen or fibrin content of inserted cannulae was also considered: The proportion of patients having received either antibiotics or anticoagulants, whether administered iv or subcutaneously, was not significantly different between groups (table 1). In contrast, the perfusion of blood products was more frequent in the low- than in the high-fibrin group $(P=.03$, Fisher's exact test), making the contribution of perfused blood products to the deposition of fibrin on inserted cannulae unlikely.

Some hematologic parameters were also compared between groups (table 2). Whereas the sedimentation rate, the number of circulating granulocytes, and the prothrombin time were not significantly different in either group, patients of the high-fibrin group had significantly higher $(P<.02$, Mann-Whitney) numbers of circulating platelets. Furthermore, the extent of $S$. aureus Wood 46 adherence was slightly higher $\left(5.06 \times 10^{3} \mathrm{cfu} / \mathrm{cm}\right)$ on the high- than on the low-fibrin cannulae $\left(3.87 \times 10^{3} \mathrm{cfu} / \mathrm{cm}, P<.05\right.$, Mann-Whitney).

To further examine a possible association between staphylococcal adherence and fibrinogen or fibrin coating of catheters, we analyzed $1-\mathrm{cm}$ segments of Hickman catheters inserted for several months in cancer patients. As shown in figure 6, statistically significant correlations between staphylococcal adherence and fibrinogen or fibrin content were found not only for $S$. aureus Cowan I $(r=.65, P<.05$, $n=10$ ), which has binding sites for surface-bound fibrinogen, but also for $S$. epidermidis $\operatorname{Rp} 12(r=$ $.75, P<.02, n=12$ ), which has none (figure 4A) [54]. Thus, although the amount of fibrinogen or fibrin deposited may help to predict the extent of staphylococcal adherence, other host proteins coat- 


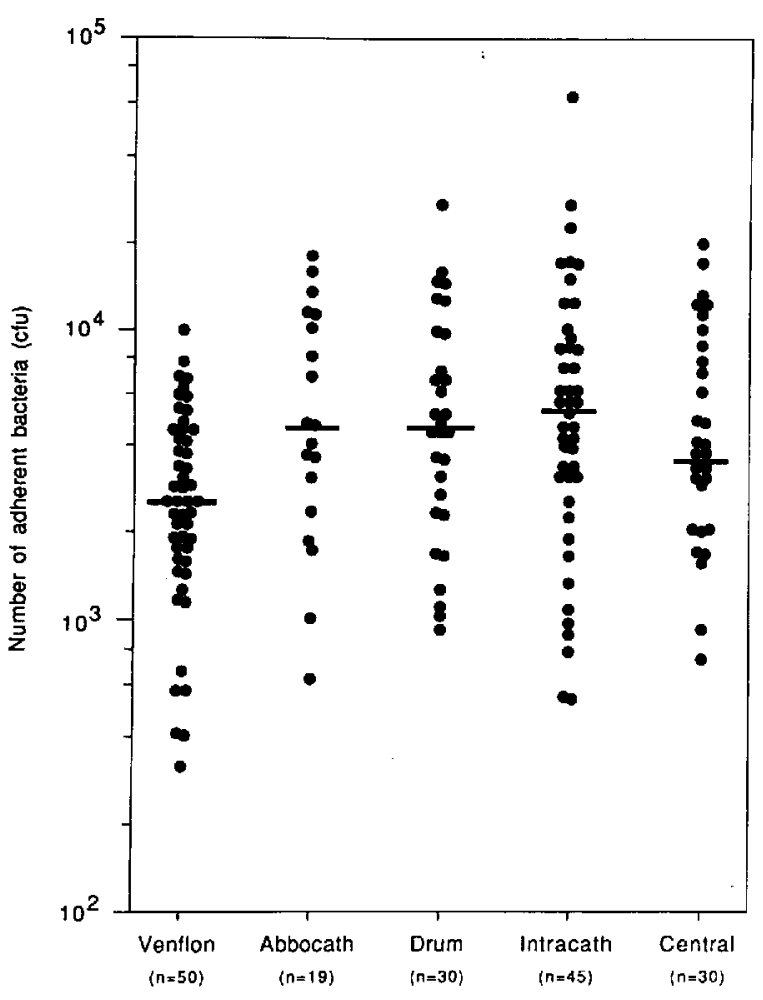

Figure 4. Promotion of $S$. aureus Wood 46 adherence on duplicate $1-\mathrm{cm}$ segments of peripheral or central inserted catheters of five different types. Adherence values for uninserted, albumin-coated cannulae ranged from 3.3 $\times 10^{2}$ to $1.0 \times 10^{3} \mathrm{cfu} / \mathrm{cm}$ (not shown). For each group, adherence on uninserted cannulae was significantly lower $(P<.01)$ than adherence on inserted ones. Bars indicate median values for each group.

Table 1. Clinical complications and commonly used perfusion products affecting fibrin deposition on inserted cannulae.

\begin{tabular}{lccc}
\hline & \multicolumn{2}{c}{ No. of patients } \\
\cline { 2 - 3 } & $\begin{array}{c}\text { Low-fibrin } \\
\text { group } \\
(n=19)\end{array}$ & $\begin{array}{c}\text { High-fibrin } \\
\text { group } \\
(n=15)\end{array}$ & \\
\hline Characteristic & & & \\
\hline Clinical complication & 7 & 2 & .06 \\
$\quad$ Macroscopic thrombus & 2 & 2 & NS \\
Perfused product & 11 & 7 & NS \\
Antibiotics & 3 & 2 & NS \\
Anticoagulant iv & 3 & 2 & NS \\
Anticoagulant se & 6 & 1 & .03 \\
Blood & & & \\
\hline
\end{tabular}

NOTE. Low-fibrin group $=0.2-4.7 \mu \mathrm{g} / \mathrm{cm}$ of cannula; highfibrin group $=8.1-112 \mu \mathrm{g} / \mathrm{cm}$; iv $=$ intravenously; $\mathrm{sc}=$ subcutaneously.

* Two-tailed Fisher's exact test.

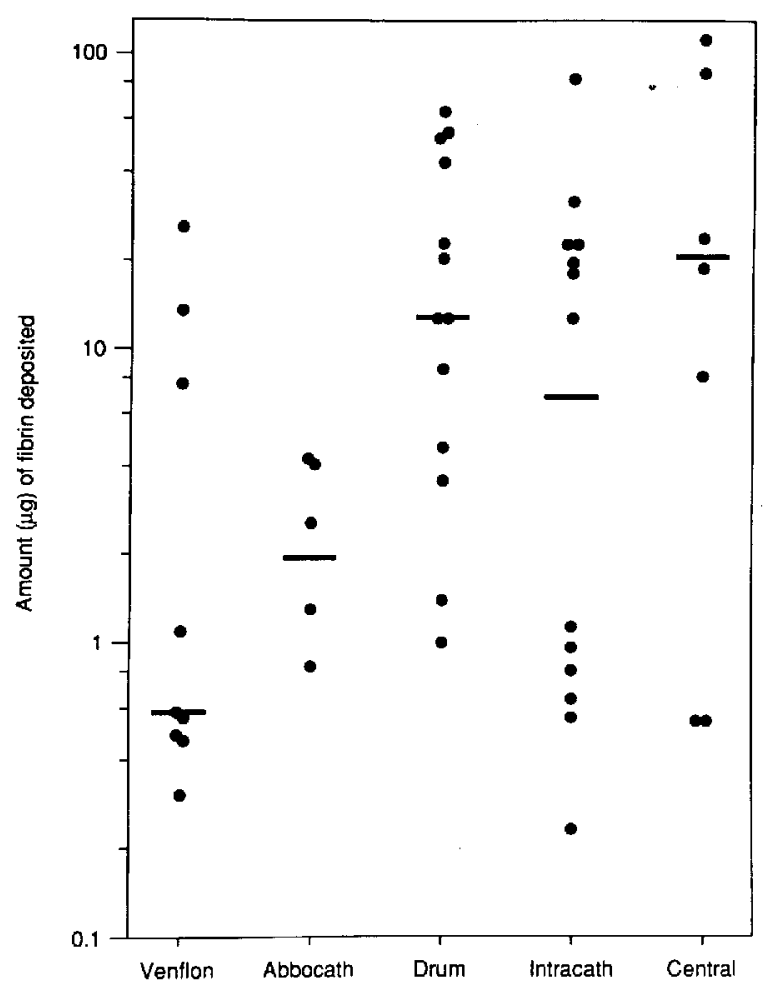

Figure 5. Amount of fibrinogen or fibrin deposited on 1-cm segments of peripheral or central inserted catheters of five different types. Bars indicate median values for each group.

ing catheter surfaces probably contribute to the adherence of coagulase-negative staphylococci.

\section{Discussion}

The present study was undertaken to define the role of blood components, deposited on the surface of inserted cannulae, in modulating staphylococcal adherence to these devices by comparing clinical samples of iv catheters with native, uninserted devices coated with various proteins.

The various catheter materials tested - the short Teflon and long PVC peripheral lines - reacted much as did PMMA [48, 49] and Teflon [50] coverslips and PVC tissue culture plates [51]. For all native, uninserted materials tested, whatever their shape, the presence of albumin in the incubation medium or on the surfaces of the material prevented staphylococcal adherence. This lack of adherence was observed with the three test strains of staphylococci as well as with the 10 bacteremic strains isolated from iv device infections in a previous study 

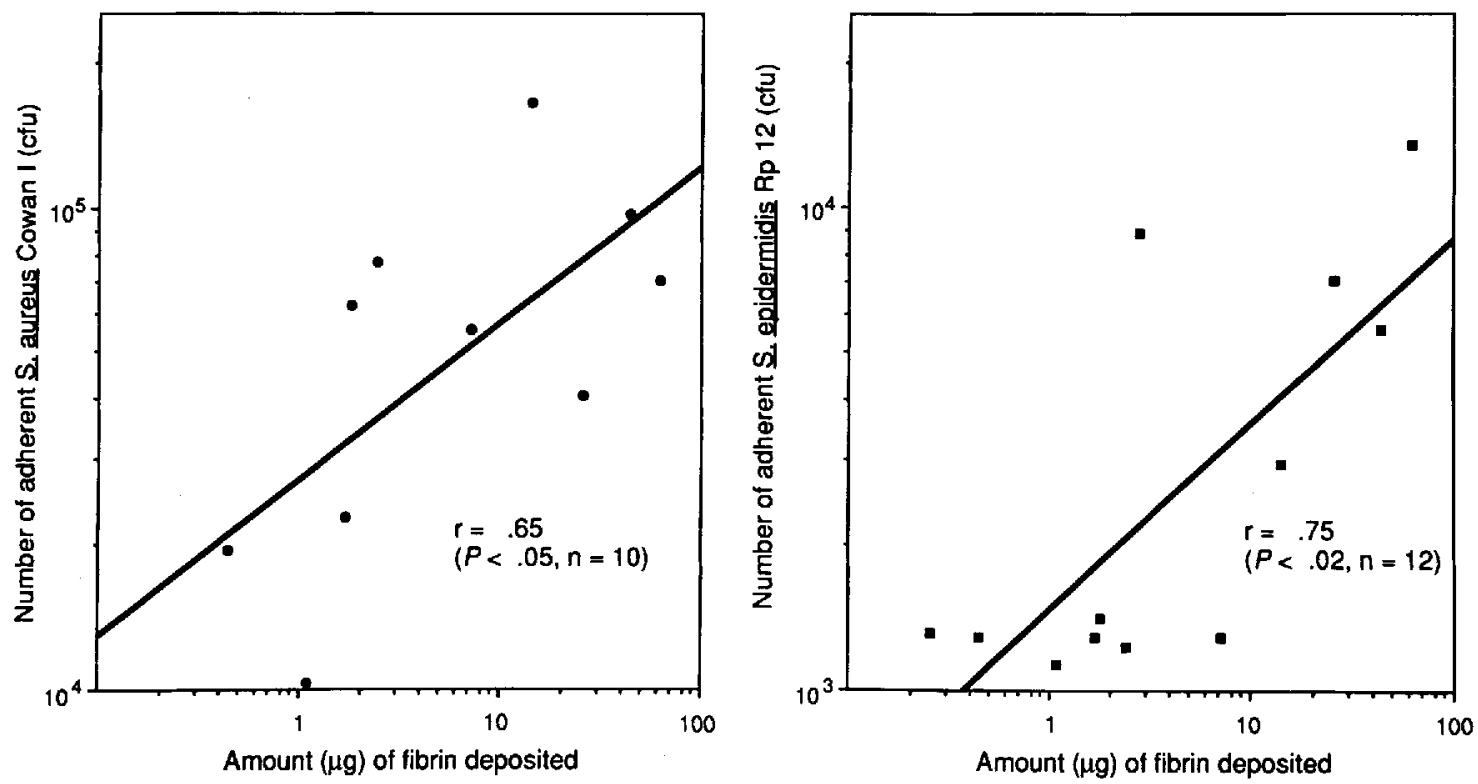

Figure 6. Relationship between number of staphylococci adherent to 1-cm sections of previously inserted Hickman catheters and their content in total fibrinogen or fibrin. Two strains are compared, $S$. aureus Cowan I ( $\bullet$ ), which has a high affinity for surface-bound fibrinogen, and $S$. epidermidis $\operatorname{Rp} 12(\square)$, which has no affinity for it. Values are means of duplicate determinations; Pearson's product moment correlation coefficients were computed from the $\log$ values of adherence and fibrinogen or fibrin content.

[52]. These data extend our previous results showing a general inhibition by albumin of staphylococcal adherence to native polymers, which applies to all types of materials and species of staphylococci tested thus far [48-52]. Work in progress in our laboratory indicates also that the recently introduced polyurethane cannulae do not allow significant

Table 2. Hematologic profile and bacterial adherence to catheters as a function of the amount of fibrin deposited in vivo on the catheters.

\begin{tabular}{|c|c|c|c|c|c|}
\hline \multirow[b]{3}{*}{ Hematologic value } & \multicolumn{4}{|c|}{$\begin{array}{c}\text { Median value } \\
\text { (no. of patients tested) }\end{array}$} & \multirow[b]{2}{*}{$P^{*}$} \\
\hline & \multicolumn{2}{|c|}{$\begin{array}{l}\text { Low-fibrin } \\
\text { group }\end{array}$} & \multicolumn{2}{|c|}{$\begin{array}{l}\text { High-fibrin } \\
\text { group }\end{array}$} & \\
\hline & & & & & \\
\hline $\begin{array}{l}\text { Sedimentation rate } \\
(\mathrm{mm} / \mathrm{h})\end{array}$ & 27 & (18) & 12 & (11) & NS \\
\hline $\mathrm{PMNL} \times 10^{9} / \mathrm{l}$ & 8.8 & (19) & 8.8 & (15) & NS \\
\hline Platelets $\times 10^{9} / 1$ & 206 & (15) & 255 & (15) & .02 \\
\hline Prothrombin time (\%) & 85 & (18) & 80 & (15) & NS \\
\hline \multicolumn{6}{|l|}{ Adherence of $S$. aureus } \\
\hline Wood $46\left(\mathrm{cfu} \times 10^{3}\right)$ & \multicolumn{2}{|c|}{$3.87(19)$} & \multicolumn{2}{|c|}{$5.06(15)$} & .047 \\
\hline
\end{tabular}

NOTE. Low-fibrin group $=0.2-4.7 \mu \mathrm{g} / \mathrm{cm}$ of cannula; highfibrin group $=8.1-112 \mu \mathrm{g} / \mathrm{cm}$.

* Two-tailed Mann-Whitney test. staphylococcal adherence in the presence of albumin (unpublished data).

In vitro precoating of uninserted catheters with fibronectin significantly promoted the adherence of each staphylococcal strain tested. The adherence of $S$. aureus Cowan I, which has the highest affinity for fibronectin-coated PMMA coverslips, was also more strongly promoted than that of either strain Wood 46 of $S$. aureus or Rp 12 of S, epidermidis on both fibronectin-coated Teflon (figure 2) and PVC (not shown) cannulae.

In vitro precoating of either uninserted catheters or PMMA coverslips with a preparation of fibrinogen that had been thoroughly depleted of fibronectin selectively promoted the adherence of only two of the three laboratory strains: Adherence of $S$. aureus Cowan I was promoted more than that of $S$. aureus Wood 46 whereas adherence of $S$. epidermidis Rp 12 was negligible. In a recent report [52] we demonstrated that adherence of most bacteremic clinical isolates of coagulase-negative staphylococci was poorly promoted by surface-bound fibrinogen, because these organisms lack fibrinogen-binding factor [29-32], also called clumping factor [30, 54].

Inserted catheters tested for staphylococcal adherence after being removed from patients promoted 
adherence of the three laboratory strains of staphylococci and of the 10 bacteremic isolates from iv device infections. In this respect, the role of plasma proteins deposited on inserted cannulae is suggested by the fact that the most adhesive laboratory strain to either fibronectin or fibrinogen ( $S$. aureus Cowan I) showed the highest binding to inserted cannulae whereas the least adhesive strain, $S$. epidermidis $\mathrm{Rp}$ 12 , which recognizes only surface-bound fibronectin, was also the least adherent. These similarities between catheters exposed in vivo and the same materials treated in vitro with host adhesins suggest a significant role for fibrinogen or fibrin and fibronectin adsorbed on inserted cannulae in promoting staphylococcal adherence in the clinical situation.

An interesting aspect of our study was the specific immunoassay to estimate total fibrinogen or fibrin deposited on previously inserted cannulae. The ubiquity of fibrinogen or fibrin on many samples randomly tested confirms previous reports suggesting the presence of a fibrin sheath surrounding inserted cannulae as detected by electron microscopy $[55,56]$. Because we found no catheter section devoid of fibrinogen or fibrin, our data suggest that the intravascular part of catheters is extensively covered by fibrinogen or fibrin possibly associated with other proteins such as fibronectin.

The omnipresence of fibrinogen or fibrin on cannula surfaces suggests a direct role for this multilayered protein in promoting staphylococcal adherence on inserted materials, a conclusion supported by two major arguments: Surface-bound fibrinogen is known to have binding sites for coagulase-positive staphylococci $[32,52]$ and $S$. aureus Cowan I, which has a higher affinity for fibrinogen than $S$. aureus Wood 46, also showed a higher adherence on inserted cannulae.

In contrast, surface-bound fibrinogen or fibrin cannot promote per se adherence of the clumping factor-negative strain Rp 12 of S. epidermidis, whose adherence is more likely promoted by surface-bound fibronectin. In this situation, fibrinogen or fibrin may still be assumed to play a significant role by holding fibronectin and presenting this proadhesive protein on the outermost surface of the protein layer coating the cannula. It is well known that plasma fibronectin is incorporated into fibrin clots by the cross-linking action of coagulation factor XIIIa [57, 58]. Thus, fibronectin may be deposited on a cannula during the formation of a fibrin film on its surface. Furthermore, Toy et al. [59] have shown that the presence of fibronectin in fibrin clots formed in vitro promoted adherence of $S$. aureus to thrombi. Finally, although laminin, another host-derived adhesin, might be considered to play a role in staphylococcal adherence to iv devices, this possibility is far more likely for $S$. aureus than for coagulase-negative strains according to our previous study [52].

Further studies are in progress in our laboratory to characterize more precisely the composition of the outermost layer of blood components deposited on cannulae and quantify the amount of surface-bound fibronectin on previously inserted cannulae.

In conclusion, this study suggests that host factors interacting with inserted intravenous catheters may play a significant role in the early steps of staphylococcal adherence, colonization, and infection. Further studies are needed to understand the sequence of events involved in cannula colonization and to define how and when bacterial factors such as slime formation may influence catheter-related infections.

\section{References}

1. Maki DG. Infections associated with intravascular lines. In: Remington JS, Swartz MN, eds. Current clinical topics in infectious diseases. Vol 3. New York: McGraw-Hill, 1982:309-363

2. Colignon PJ, Munro R, Sorrell TC. Systemic sepsis and intravenous devices. Med J Aust 1984;141:345-348

3. Hamory BH. Nosocomial bloodstream and intravascular device-related infections. In: Wenzel RP, ed. Prevention and control of nosocomial infections. Baltimore: Williams and Wilkins, 1987:282-319

4. Maki DG. Epidemic nosocomial bacteremias. In: Wenzel RP, ed. Handbook of hospital acquired infections. Boca Raton, Fla: CRC Press, 1982:371-512

5. Rose HD. Venous catheter-associated candidemia. Am J Med Sci 1978;275:265-269

6. Maki DG, Weise CE, Sarafin HW. A semiquantitative culture method for identifying intravenous-catheter-related infection. N Engl J Med 1977;296:1305-1309

7. Stillman RM, Soliman F, Garcia L, Sawyer PN. Etiology of catheter-associated sepsis. Correlation with thrombogenicity. Arch Surg 1977;112:1496-1499

8. Tager I, Ginsberg MB, Ellis SE, Walsh NE, Dupont I, Simchen E, Faich GA. An epidemiologic study of the risks associated with peripheral intravenous catheters. Am J Epidemiol 1983;118:839-851

9. Zimmerli W, Waldvogel FA, Vaudaux P, Nydegger UE. Pathogenesis of foreign body infection: description and characteristics of an animal model. J Infect Dis 1982;146:487-497

10. Wilkins EGL, Manning D, Roberts C, Davidson DC. Quantitative bacteriology of peripheral venous cannulae in neonates. J Hosp Infect 1985;6:209-217 
11. Moyer MA, Edwards LD, Farley L. Comparative culture methods on 101 intravenous catheters. Routine, semiquantitative, and blood cultures. Arch Intern Med 1983;143: 66-69

12. Henderson DK. Bacteremia due to percutaneous intravascular devices. In: Mandell GL, Douglas RG Jr, Bennett JE, eds. Principles and practice of infectious diseases. 2nd ed. New York: John Wiley \& Sons, 1985:1612-1620

13. Lowy FD, Hammer SM. Staphylococcus epidermidis infections. Ann Intern Med 1983;99:834-839

14. Christensen GD, Bisno AL, Parisi JT, McLaughlin B, Hester MG, Luther RW. Nosocomial septicemia due to multiply antibiotic-resistant Stophylococcus epidermidis. Ann Intern Med 1982;96:1-10

15. Christensen GD, Simpson WA, Bisno AL, Beachey EH. Adherence of slime-producing strains of Staphylococcus epidermidis to smooth surfaces. Infect Immun 1982;37: 318-326

16. Peters G, Locci R, Pulverer G. Microbial colonization of prosthetic devices. II. Scanning electron microscopy of naturally infected catheters. Zentralblatt fur Bakteriologie, Mikrobiologie und Hygiene. 1. Abt. Originale B, Hygiene 1981;173:293-299

17. Peters G, Locci R, Pulverer G. Adherence and growth of coagulase-negative staphylococci on surfaces of intravenous catheters. J Infect Dis 1982;146:479-482

18. Marrie TJ, Costerton JW. Scanning and transmission electron microscopy of in situ bacterial colonization on intravenous and intraarterial catheters. J Clin Microbiol 1984; 19:687-693

19. Franson TR, Sheth NK, Rose HD, Sohnle PG. Scanning electron microscopy of bacteria adherent to intravascular catheters. J Clin Microbiol 1984;20:500-505

20. Christensen GD, Simpson WA, Younger JJ, Baddour M, Barrett FF, Melton DM, Beachey EH. Adherence of coagulasenegative staphylococci to plastic tissue culture plates: a quantitative model for adherence of staphylococci to medical devices. J Clin Microbiol 1985;22:996-1006

21. Tenney JH, Moody MR, Newman KA, Schimpff SC, Wade JC, Costerton JW, Reed WP. Adherent microorganisms on lumenal surface of long-term intravenous catheters. Importance of Staphylococcus epidermidis in patients with cancer. Arch Intern Med 1986;146:1949-1954

22. Ishak MA, Gröschel DHM, Mandell GL, Wenzel RP. Association of slime with pathogenicity of coagulase-negative staphylococci causing nosocomial septicemia. J Clin Microbiol 1985;22;1025-1029

23. Costerton JW, Irvin RT, Cheng KJ. The bacterial glycocalyx in nature and disease. Annu Rev Microbiol 1981;35:299-324

24. Gristina AG, Costerton JW. Bacterial adherence to biomaterials and tissues. J Bone Joint Surg [Am] 1985; 67A:264-273

25. Peters G, Schumacher-Perdreau F. Bacterial slime and infections of prosthetic devices and intravascular catheters. In: Peterson PK, Fleer A, eds. Third European Congress for Microbiology symposium on foreign body-related infections. Amsterdam: Excerpta Medica, 1987:16-25

26. Gray ED, Peters G, Vestegen M, Regelmann WE. Effects of extracellular slime substance from Staphylococcus epidermidis on the human cellular immune response. Lancet 1984;1:365-367
27. Johnson GM, Lee DA, Regelmann WE, Gray ED, Peters G, Quie PG. Interference with granulocyte function by Staphylococcus epidermidis slime. Infect Immun 1986;54:13-20

28. Sheth NK, Franson TR, Sohnle PG. Influence of bacterial adherence to intravascular catheters on in vitro antibiotic susceptibility. Lancet 1985;2:1266-1268

29. Hawiger J, Timmons S, Strong DD, Cottrell BA, Riley M, Doolittle RF. Identification of a region of human fibrinogen interacting with staphylococcal clumping factor. Biochemistry 1982;21:1407-1413

30. Usui Y. Biochemical properties of fibrinogen binding protein (clumping factor) of the staphylococcal cell surface. Zentralbl Bakteriol Mikrobiol Hyg [A] 1986;262:287-297

31. Lämmler C, de Freitas JC, Chhatwal GS, Blobel H. Interactions of immunoglobulin $\mathrm{G}$, fibrinogen and fibronectin with Staphylococcus hyicus and Staphylococcus intermedius. Zentralbl Bakteriol Mikrobiol Hyg [A] 1985; 260:232-237

32. Kuusela P, Vartio T, Vuento M, Myhre EB. Attachment of staphylococci and streptococci on fibronectin, fibronectin fragments, and fibrinogen bound to a solid phase. Infect Immun 1985;50:77-81

33. Kuusela P. Fibronectin binds to Staphylococcus aureus. Nature 1978;276:718-720

34. Mosher DF, Proctor RA. Binding and factor XIIla-mediated cross-linking of a 27-kilodalton fragment of fibronectin to Staphylococcus aureus. Science 1980;209:927-929

35. Proctor RA, Christman G, Mosher DF. Fibronectin-induced agglutination of Staphylococcus aureus correlates with invasiveness. J Lab Clin Med 1984;104:455-469

36. Vercellotti GM, Lussenhop D, Peterson PK, Furcht LT, McCarthy JB, Jacob HS, Moldow CF. Bacterial adherence to fibronectin and endothelial cells: a possible mechanism for bacterial tissue tropism. J Lab Clin Med 1984; 103:34-43

37. Vercellotti GM, McCarthy JB, Lindhom P, Peterson PK, Jacob HS, Furcht LT. Extracellular matrix proteins (fibronectin, laminin, and type IV collagen) bind and aggregate bacteria. Am J Pathol 1985;120:13-21

38. Kuusela $P$, Vartio $T$, Vuento $M$, Myhre EB. Binding sites for streptococci and staphylococci in fibronectin. Infect Immun 1984;45:433-436

39. Proctor RA, Mosher DF, Olbrantz PJ. Fibronectin binding to Staphylococcus aureus. J Biol Chem 1982;257:1478814794

40. Ryden C, Rubin K, Speziale P, Höök M, Lindberg M, Wadström T. Fibronectin receptors from Staphylococcus aureus. J Biol Chem 1983;258:3396-3401

41. Switalski LM, Ryden C, Rubin K, Ljungh A, Höök M, Wadström T. Binding of fibronectin to staphylococcus strains. Infect Immun 1983;42:628-633

42. Scheld WM, Strunk RW, Balion G, Colderone RA. Microbial adhesion to fibronectin in vitro correlates with production of endocarditis in rabbits. Proc Soc Exp Biol Med $1985 ; 180: 474-482$

43. Maxe I, Ryden C, Wadström T, Rubin K. Specific attachment of Staphylococcus aureus to immobilized fibronectin. Infect Immun 1986;54:695-704

44. Fröman G, Switalski LM, Speziale P, Höök M. Isolation and characterization of a fibronectin receptor from Staphylococcus aureus. J Biol Chem 1987;262:6564-6571 
45. Flock JI, Fröman G, Jönsson K, Guss B, Signäs C, Nilsson B, Raucci G, Höök M, Wadström T, Lindberg M. Cloning and expression of the gene for a fibronectin-binding protein from Staphylococcus aureus. EMBO J 1987;6: 2351-2357

46. Lopez JD, Dos Reis M, Brentani RR. Presence of laminin receptors in Staphylococcus aureus. Science 1985;21: 1407-1413

47. Holderbaum D, Spech RA, Erhadt LA. Specific binding sites of collagen to Staphylococcus aureus. Coll Relat Res 1985;5:261-271

48. Vaudaux $\mathbf{P}$, Suzuki $\mathbf{R}$, Waldvogel FA, Morgenthaler $\mathbf{J}$, Nydegger UE. Foreign body infection: role of fibronectin as a ligand for the adherence of Staphylococcus aureus. J Infect Dis 1984;150:546-553

49. Vaudaux PE, Waldvogel FA, Morgenthaler JJ, Nydegger UE. Adsorption of fibronectin onto polymethylmethacrylate and promotion of Staphylococcus aureus adherence. Infect Immun 1984;45:62-73

50. Vaudaux $P$, Lerch $P$, Velazco MI, Nydegger UE, Waldvogel FA. Role of fibronectin in the susceptibility of biomaterial implants to bacterial infections. In: Christel P, Meunier A, Lee AJC, eds. Biological and biomechanical performance of biomaterials. Amsterdam: Elsevier, 1986:355-360

51. Velazco MI, Waldvogel FA. Monosaccharide inhibition of Staphylococcus aureus adherence to human solid-phase fibronectin. J Infect Dis 1987;155:1069-1072

52. Herrmann M, Vaudaux P, Pittet D, Auckenthaler R, Lew PD,
Schumacher-Perdreau F, Peters G, Waldvogel FA. Fibronectin, fibrinogen, and laminin act as mediators of adherence of clinical staphylococcal isolates to foreign material. $\mathbf{J}$ Infect Dis 1988;158:693-701

53. Haeberli A, Straub PW. Quantitative determination of fibrin and fibrinogen in biological material. J Lab Clin Med 1980;96:258-266

54. Jeljaszewicz J, Switalski LM, Adlam C. Staphylocoagulase and clumping factor. In: Easmon CSF, Adlam C, eds. Staphylococci and staphylococcal infections. Vol 2. London: Academic Press, 1983:525-557

55. Hoshal VL, Ause RG, Hoskins PA. Fibrin sleeve formation on indwelling subclavian central venous catheters. Arch Surg 1971;102:353-358

56. Peters WR, Bush WH, McIntyre R, Hill LD. The development of fibrin sheath on indwelling venous catheters. Surg Gynecol Obstet 1973;137:43-47

57. Mosher DF, Proctor RA, Grossman JE. Fibronectin: role in inflammation. In: Weissman G, ed. Advances in inflammation research. Vol 2. New York: Raven Press, 1981: 187-206

58. Grinnell F, Feld M, Minter D. Fibroblast adhesion to fibrinogen and fibrin substrata: requirement for cold-insoluble globulin (plasma fibronectin). Cell 1980;19:517-525

59. Toy PTCY, Lai L, Drake TA, Sande MA. Effect of fibronectin on adherence of Staphylococcus aureus to fibrin thrombi in vitro. Infect Immun 1985;48:83-86 